\title{
So werden langsame Praxisrechner wieder schneller
}

\author{
Quält sich der Praxis-PC bei jeder Eingabe und jedem Speichervorgang, \\ wird es Zeit, die Speicherkapazität zu erweitern. Eine neue Technik soll \\ hier Wunder wirken.
}

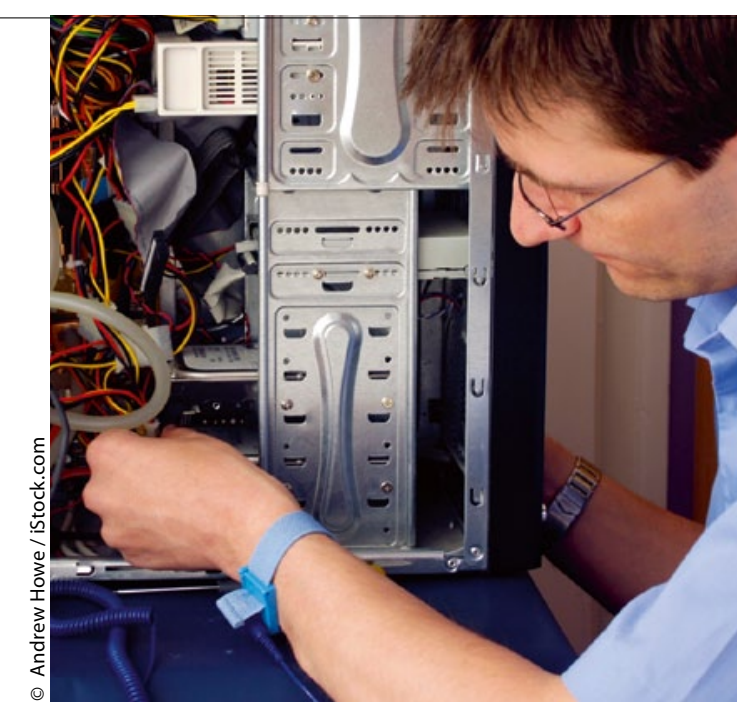

sicht erforderlich ist, damit keine Daten verloren gehen oder beschädigt werden.

rende Magnetscheibe und speichern die PC-Daten auf spezialisierten Chips, wie sie in Smartphones und Tablet-PC schon längst gang und gäbe sind. Der Name „Solid State Drive“ bezeichnet im Computerslang dieses Prinzip: Ein Speicherlaufwerk (Drive) in festem Zustand (Solid State) das heißt: ohne rotierende Mechanik. Das bringt einige Vorteile: Der elektronische Speicher ist unempfindlich gegen mechanische Erschütterungen und verbraucht weniger Strom. Der größte Gewinn ist aber: SSD lesen und schreiben Daten erheblich schneller, als die gute alte Festplatte. Und dieser Unterschied ist frappierend.

\section{PC-Jungbrunnen durch Datenumzug}

Julia Molzen vom Hersteller Buffalo: „Allein durch den Austausch der alten Festplatte durch ein SSD-Speicherlaufwerk lässt sich das Arbeitstempo auch betagter Rechner massiv steigern. “ Denn der Zugriff auf Programme und Daten habe größeren Anteil an der Arbeitsleistung eines PC, als etwa die Geschwindigkeit der Rechenvorgänge im Prozessor. Wer vorhandene Computer oder Notebooks mit vergleichsweise geringem Aufwand „tunen“ möchte, sollte seinem PC-Händler oder dem mit dem Hardware-Support betrauten Unternehmen deshalb den Wechsel zur modernen SSD-Technik vorschlagen.

Da SSD-Laufwerke dieselben Anschlüsse und Standards verwenden wie ihre technischen Vorgänger, die Festplatten, ist der Austausch vergleichsweise unkompliziert. Er sollte aber dennoch von einem versierten PC-Spezialisten vorgenommen werden - zumal beim „Umzug“ von Daten und Programmen von der alten Festplatte auf die neue SSD besondere Vor-

\section{Neue Technik hat ihren Preis}

Bei allen Vorzügen, gibt es bei den neuen, schnellen Speicherlaufwerken jedoch auch Einschränkungen zu beachten. Der wohl wichtigste Punkt: SSD-Laufwerke sind im Vergleich zu Festplatten deutlich teurer. Während man für $200 €$ eine handelsübliche Festplatte mit 3 Terabyte (rund 3.000 Gigabyte, GB) Kapazität erhält, erwirbt dasselbe Budget SSD-Technik nur mit 64 bis 128 GB Kapazität. Große SSD mit 600 GB kosten etwa 900 $€$. Wer mit sehr großen Datenmengen zu tun hat (etwa auf der Festplatte seines Praxis-PC seine Ultraschall- und Röntgen-Bilder, szinitigrafische Aufnahmen, Bildergebnisse konsiliarischer Untersuchungen oder andere Bilddaten archiviert), sollte deshalb überlegen, ob er eventuell die schnelle, aber teure SSD mit einer langsameren, aber mehr Speicherkapazität bietenden Festplatte kombiniert. Betriebssystem und Programme werden dann im PC auf der SSD gespeichert, umfangreiche Daten wie Bilder und ähnliches auf der Festplatte.

Ein weiterer Aspekt: Auch SSD sind keine Datenfestungen - man sollte sich nie auf nur ein Laufwerk verlassen, wenn es um die Sicherheit und Langlebigkeit der darauf gespeicherten Daten geht. Die auf beiden Speichermedien abgelegten Daten sollten deshalb unbedingt durch Backups gegen Defekte, Fehlfunktionen oder versehentliches Löschen zusätzlich geschützt werden. Für solche Backups ist eine separate, zweite Festplatte dank ihrer Kapazitätsvorteile übrigens nach wie vor eine gute Wahl. Hannes Rügheimer 